\title{
Geo-mapping of time trends in childhood caries risk - a method for assessment of preventive care
}

Ulf Strömberg ${ }^{1,2^{*}}$, Anders Holmén ${ }^{1}$, Kerstin Magnusson ${ }^{3}$ and Svante Twetman ${ }^{3,4}$

\begin{abstract}
Background: Dental caries is unevenly distributed within populations with a higher burden in low socio-economy groups. Several attempts have been made to allocate resources to those that need them the most; there is a need for convenient approaches to population-based monitoring of caries risk over time. The aim of this study was to develop the geo-map concept, addressing time trends in caries risk, and demonstrate the novel approach by analyzing epidemiological data from preschool residents in the region of Halland, Sweden.

Methods: The study population consisted of 9,973 (2006) and 10,927 (2010) children between 3 to 6 years of age ( $77 \%$ of the eligible population) from whom caries data were obtained. Reported dmfs $>0$ for a child was considered as the primary caries outcome. Each study individual was geo-coded with respect to his/her residence parish (66 parishes in the region). Smoothed caries risk geo-maps, along with corresponding statistical certainty geo-maps, were produced by using the free software Rapid Inquiry Facility and the ESRI ${ }^{\circledR}$ ArcGIS system. Parish-level socioeconomic data were available.

Results: The overall proportion of caries-free $(\mathrm{dmfs}=0)$ children improved from $84.0 \%$ in 2006 to $88.6 \%$ in 2010 . The ratio of maximum and minimum (parish-level) smoothed relative risks (SmRRs) increased from 1.76/0.44=4.0 in 2006 to $2.37 / 0.33=7.2$ in 2010, which indicated an increased geographical polarization of early childhood caries in the population. Eight parishes showed evidential, positional changes in caries risk between 2006 and 2010; their corresponding SmRRs and statistical certainty ranks changed markedly. No considerable parallel changes in parishlevel socioeconomic characteristics were seen during the same time period.

Conclusion: Geo-maps based on caries risk can be used to monitor changes in caries risk over time. Thus, geomapping offers a convenient tool for evaluating the effectiveness of tailored health promotion and preventive care in child populations.
\end{abstract}

Keywords: Caries, Children, Prevention, Geo-mapping, Time trend

\section{Background}

The prevalence of dental caries has declined globally over the past decades but all children have not benefited from the improved oral health. Widening inequalities between social classes and certain minority ethnic groups are evident [1-5]. Caries risk assessment (CRA) is an essential component in the decision-making process for the prevention and management of the disease [6]. For individuals, background data on host factors, diet and oral hygiene are commonly merged with findings from a

\footnotetext{
* Correspondence: ulf.a.stromberg@regionhalland.se

'Department of Research and Development, Halland Hospital, SE-301 85, Halmstad, Sweden

${ }^{2}$ Department of Occupational and Environmental Medicine, Lund University, SE-221 85, Lund, Sweden

Full list of author information is available at the end of the article
}

clinical examination while CRA in populations most often rely on epidemiological data and/or socioeconomic determinants. An increased caries risk should preferably be linked to intensified preventive and nonoperative care and many such initiatives have been launched globally [7-9]. However, the lack of convenient and effective tools to monitor the outcome of such health promoting activities has limited the evaluation of effectiveness. There is a need for new approaches to population-based monitoring of caries risk over time.

In a recent paper we suggested the use of geo-maps for presenting epidemiological data based on childhood caries risk in a Swedish population and we advocated this novel approach for allocation of preventive care [10]. In order to evaluate the effect of preventive measures on childhood 
caries, there is a need for a method that compares repeated geo-maps. In the present communication, the geo-map concept is developed to address time trends in caries risk. We demonstrate the novel approach by analyzing and examining time trends in childhood caries risk (36 years) based on epidemiological data from two occasions over four years in the southwest Swedish region of Halland.

\section{Methods}

\section{Study population}

The vast majority of all children (around 90\%) in the region are listed as regular patients at the Public Dental Service that provides free dental care between 1 and 19 years with recall intervals varying from 3 to 24 months depending on the individual need. Data on the experience of manifest (dentin) caries is registered according to the $\mathrm{WHO}$-criteria [11] and annually reported to the community dentistry unit. The fluoride concentration in piped water supply is generally low $(<0.3 \mathrm{ppm})$ except in the northern part (the municipality of Kungsbacka) where the natural fluoride content in the drinking water is approximately $1.0 \mathrm{ppm}$.

The present study included 9,973 children between 36 years of age for whom caries data were reported in 2006 and 10,927 children with corresponding data from 2010. The age distributions of the children examined in 2006 and 2010, respectively, did only differ marginally (proportions of children aged $\geq 5$ years: $49.3 \%$ in 2006 ; $50.3 \%$ in 2010). The overall coverage of the total 3-6-year population of the Halland region was $76 \%$ in 2006 and $77 \%$ in 2010. The remaining children were not recalled for a regular check-up that particular year or visited a private dentist at a clinic not among the in-reporting ones or located outside the region. The study was approved by the Halland Hospital Ethical committee as well as The Swedish Data Inspection Board.

\section{Geographical information system (GIS) methods}

The Halland region consists of six municipalities that are subdivided into 66 parishes. Geo-maps were produced by

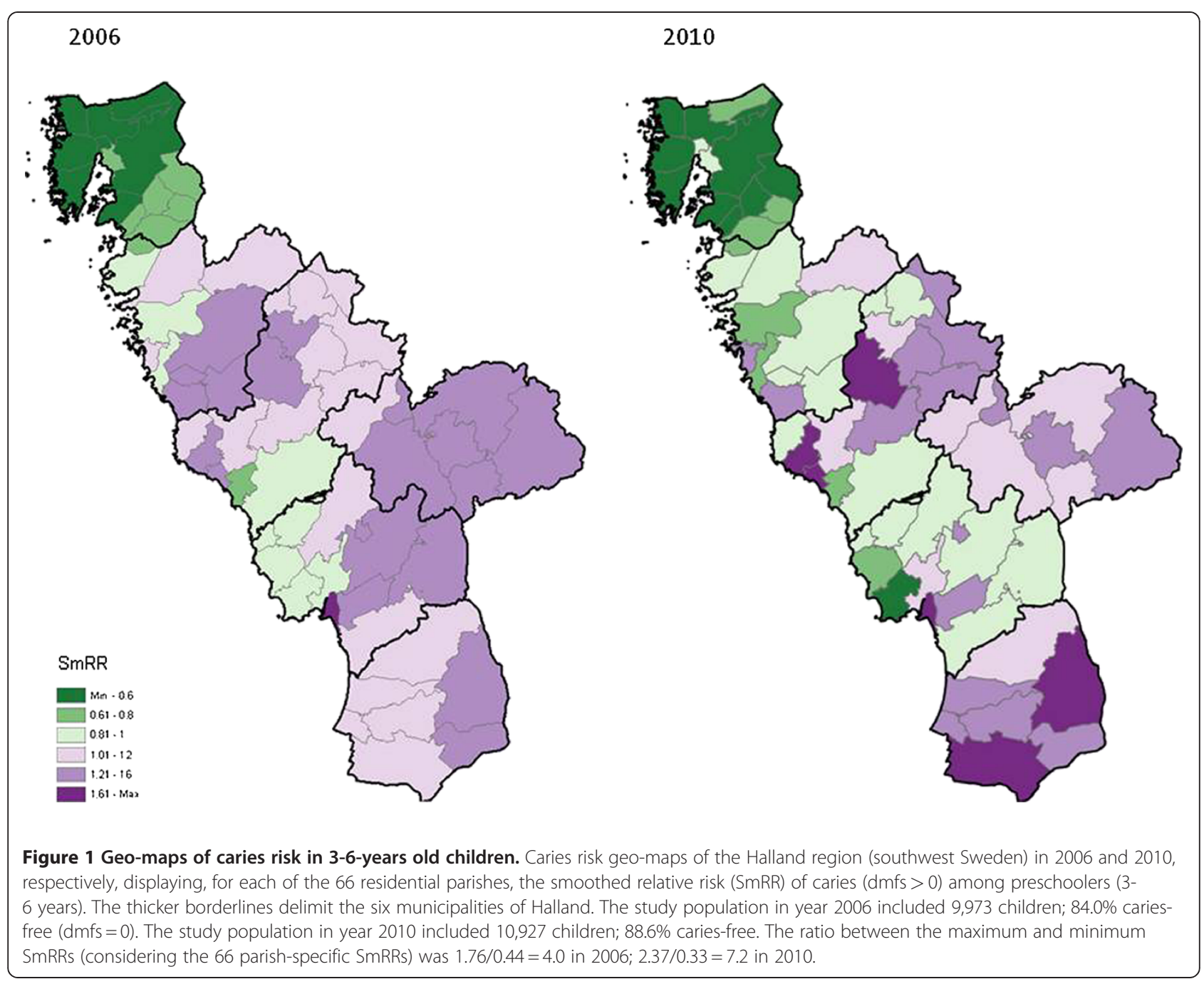


using the ESRI ${ }^{\circledR}$ ArcGIS system (Environmental Systems Research Institute, Inc., USA). Each child was geo-coded with respect to his/her residence area (parish).

\section{Socio-economic characteristics}

Statistics Sweden provided parish-level data from years 2006 and 2010, respectively, on three socio-economic indicators: (i) the proportion with post-secondary education (any schooling beyond the high-school level) among all residents; (ii) the proportion of immigrants (more specifically, individuals born outside Sweden and individuals born in Sweden with both parents born outside Sweden) among all residents; and (iii) the proportion of families with low purchasing power (according to Swedish standard; $\leq 19,500$ USD annual income) among all residing families with at least one child ( $\leq 19$ years old; family with the same residence address).

\section{Epidemiological and statistical methods}

Reported dmfs $>0$ for a child was considered as the primary caries outcome. The method for estimating caries risks at a given year of reporting has been explained previously [10]. Briefly, a parish-level relative risk (RR) was calculated as the observed-to-expected ratio, where the expected number was obtained from the sex-specific caries $(\mathrm{dmfs}>0)$ rates for the total study population of 3-6 year old children residing in the Halland region. Moreover, smoothed RRs (SmRR) for each parish were obtained by running a Bayesian hierarchical mapping model, which allow parish-specific RRs to be smoothed towards global and local average risk levels across the study region [12]. We underline that such Bayesian smoothing yielded "shrinkage" of the conventional observed-to-expected ratios. The corresponding statistical certainty geo-maps were obtained by calculating the posterior probabilities of a

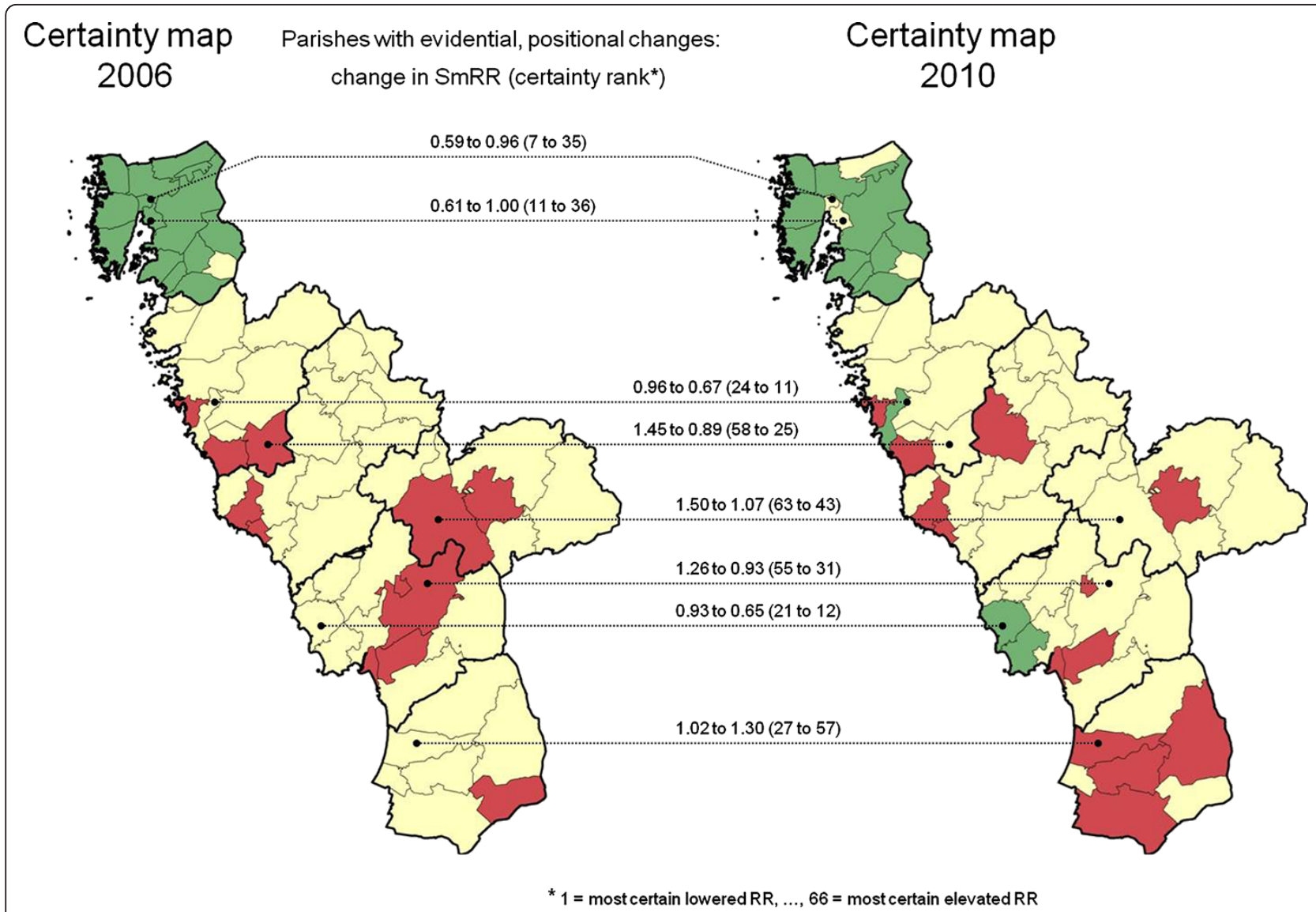

Figure 2 Certainty geo-maps of elevated/lowered relative risk of caries in 3-6-years old children; parishes with evidential, positional changes in caries risk indicated with connecting lines. Statistical certainty geo-maps of the Halland region (southwest Sweden) in 2006 and 2010, respectively, for each of the 66 residential parishes [red color, $\operatorname{Pr}(\operatorname{RR}>1$ data) $>0.95$, i.e. a parish with data yielding strong statistical evidence of an elevated caries ( $\mathrm{dmfs}>0$ ) risk; green color, $\operatorname{Pr}(\mathrm{RR}<1 \mid$ data $)>0.95$, i.e. a parish with data yielding strong statistical evidence of a lowered caries risk; and yellow color, a parish with data yielding weaker statistical evidence for a high or low relative risk]. The thicker borderlines delimit the six municipalities of Halland. The eight parishes with evidential, positional changes in caries risk are indicated with connecting lines providing information on changes in the smoothed relative risk (SmRR) and certainty rank (between 2006 and 2010). 
Table 1 Descriptive data for three socio-economic indicators on the parish-level

\begin{tabular}{|c|c|c|}
\hline \multirow[b]{2}{*}{$\begin{array}{l}\text { Socio-economic indicator } \\
\text { Parish }\end{array}$} & 2006 & 2010 \\
\hline & \multicolumn{2}{|l|}{$\begin{array}{l}\text { Range in the Halland region } \\
\text { Proportion in parish (rank }{ }^{\S} \text { ) }\end{array}$} \\
\hline $\begin{array}{l}\text { Proportion with post-secondary } \\
\text { education among all residents (\%) }\end{array}$ & $10.4-48.4$ & $10.0-48.3$ \\
\hline $7 \rightarrow 35$ & $28.8(53)$ & $29.8(54)$ \\
\hline $11 \rightarrow 36$ & $25.6(49)$ & $25.1(46)$ \\
\hline $21 \rightarrow 12$ & $32.9(60)$ & $34.8(59)$ \\
\hline $24 \rightarrow 11$ & $32.6(59)$ & $35.1(60)$ \\
\hline $27 \rightarrow 57$ & $23.2(42)$ & $23.5(42)$ \\
\hline $55 \rightarrow 31$ & $22.6(40)$ & $22.9(40)$ \\
\hline $58 \rightarrow 25$ & $24.1(46)$ & 22.7 (39) \\
\hline $63 \rightarrow 43$ & $15.0(13)$ & $15.0(13)$ \\
\hline $\begin{array}{l}\text { Proportion of immigrants among } \\
\text { all residents (\%) }\end{array}$ & 1.9-30.7 & $4.0-33.9$ \\
\hline $7 \rightarrow 35$ & $10.4(52)$ & $11.4(50)$ \\
\hline $11 \rightarrow 36$ & $6.7(29)$ & $7.4(26)$ \\
\hline $21 \rightarrow 12$ & $5.2(13)$ & $5.9(9)$ \\
\hline $24 \rightarrow 11$ & $5.7(15)$ & $6.7(18)$ \\
\hline $27 \rightarrow 57$ & $11.5(55)$ & 13.9 (55) \\
\hline $55 \rightarrow 31$ & 7.5 (37) & $8.8(37)$ \\
\hline $58 \rightarrow 25$ & $4.4(4)$ & $6.7(16)$ \\
\hline $63 \rightarrow 43$ & $12.9(58)$ & $15.3(57)$ \\
\hline $\begin{array}{l}\text { Proportion of families with low purchasing } \\
\text { power among all residing families with at } \\
\text { least one child ( } \leq 19 \text { years old) (\%) }\end{array}$ & $8.7-38.1$ & $8.2-39.5$ \\
\hline $7 \rightarrow 35$ & $20.2(35)$ & 20.9 (32) \\
\hline $11 \rightarrow 36$ & $16.6(21)$ & $18.1(24)$ \\
\hline $21 \rightarrow 12$ & $15.2(15)$ & $14.2(12)$ \\
\hline $24 \rightarrow 11$ & $11.0(6)$ & $9.2(4)$ \\
\hline $27 \rightarrow 57$ & $22.0(38)$ & $22.0(36)$ \\
\hline $55 \rightarrow 31$ & $16.5(20)$ & $17.6(21)$ \\
\hline $58 \rightarrow 25$ & $29.0(60)$ & 29.3 (57) \\
\hline $63 \rightarrow 43$ & $28.1(58)$ & 26.1 (49) \\
\hline
\end{tabular}

* Data for the eight parishes with evidential, positional changes in caries risk shown in Figure 2; identification for each parish is the certainty rank for relative risk in $2006 \rightarrow 2010$.

$\S$ Rank in the Halland region ( 1 = lowest proportion; $66=$ highest proportion).

parish-specific relative risks above 1 given the data, denoted $\operatorname{Pr}(R R>1 \mid$ data $)$, using the Bayesian approach. A parish with data yielding strong statistical evidence of an elevated caries risk, more precisely $\operatorname{Pr}(\operatorname{RR}>1 \mid$ data $)>0.95$, was colored red in the certainty geo-map. By contrast, a parish with evidently lowered caries risk, $\operatorname{Pr}(R R<1 \mid$ data $)=1-\operatorname{Pr}$ $(R R>1 \mid$ data $)>0.95$, was colored green. The remaining parishes were colored yellow, which indicates a weaker statistical evidence for an elevated/lowered relative risk.

Evidential, positional changes in the caries risk estimated for the children living in a specific parish in 2006 and 2010, respectively, were assessed by comparing the certainty geo- maps along with the posterior probabilities, $\operatorname{Pr}(R R>1 \mid$ data): if the certainty color changed and $\operatorname{Pr}(R R>1 \mid$ data $)$ differed at least $25 \%$ for a specific parish, when comparing the results for the study years 2006 and 2010, the positional change was considered "evidential". Hence, the rationale for classifying a positional change as "evidential" is based on the change over time in the statistical evidence for an elevated (or lowered) relative risk. Clearly, it seems extraordinary to observe a parish with a positional change from an evidently elevated caries risk ("red") in 2006 to an evidently lowered caries risk ("green") in 2010, or vice versa. Nevertheless, there were more modest, yet substantial, positional 
changes (from "red"/"green" to "yellow", or vice versa) that we considered evidential. Also notice that a parish could change certainty color without being indentified to have an evidential positional change (provided $\operatorname{Pr}(\mathrm{RR}>1 \mid$ data) differed less than 25\%).

The statistical analyses were performed using the free software Rapid Inquiry Facility [13], which provides an extension to ESRI ${ }^{\circledR}$ ArcGIS functions [14], along with free software for Bayesian data analyses, WinBUGS [15].

\section{Results}

The geo-maps of early childhood caries risk in 2006 and 2010, respectively, are presented in Figure 1. The overall proportion of caries-free $(\mathrm{dmfs}=0)$ children improved from $84.0 \%$ in 2006 to $88.6 \%$ in 2010 . The geographical variation in caries risk was obvious in both years. The ratio between the maximum and minimum parish-level SmRRs increased from $1.76 / 0.44=4.0$ in 2006 to 2.37 / $0.33=7.2$ in 2010, which indicated accentuation of the geographical polarization of early childhood caries in the population. The corresponding statistical certainty geomaps are presented in Figure 2. The eight parishes with evidential, positional changes in caries risk are indicated with connecting lines. For nine parishes, an evidently elevated relative risk in 2006 was weakened in 2010 (from "red" to "yellow", $\mathrm{n}=4$ ), or vice versa (from "yellow" to "red", $n=5$ ). The positional changes in caries risk were considered evidential in four of those parishes. For six parishes, an evidently lowered risk in 2006 had weakened evidence in 2010 (from "green" to "yellow", n= 3), or vice versa (from "yellow" to "green", $\mathrm{n}=3$ ). The positional changes in caries risk were considered evidential in four of those parishes. There were marked changes in SmRRs as well as in certainty rank $(1=$ most certain lowered relative risk; $66=$ most certain elevated relative risk) for the parishes showing evidential changes. For example, in a parish in the northern part of the region, with $\operatorname{SmRR}=0.59$ and among the top-10 according to certainty rank in 2006 (262 study children; 90.5\% cariesfree; $\mathrm{dmfs}=0$ ), the SmRR increased to 0.96 and the certainty rank fell to 35 in 2010 (308 study children; 88.0\% caries-free).

For the eight parishes showing evidential positional changes in caries risk, no notable parallel changes in the parish-level socioeconomic characteristics were seen (Table 1). Although the proportion of immigrants increased over the time period, the rank positions of the parishes at issue were similar in 2006 and 2010, respectively (Table 1).

\section{Discussion}

We demonstrated that geo-maps based on caries risk can be used to monitor changes in caries risk over time. An important finding from the present study was that the geo-map concept was sensible enough for disclosing changes in geographical caries risk patterns among preschool children over a 4-year period, in spite of minor changes in absolute caries risk and stable contextual socioeconomic characteristics. We also underline that the Bayesian smoothing of the relative risks yielded essentially conservative estimates, meaning moderate sensitivity but high specificity [16]. The "regression to the mean" problem, i.e. the phenomenon that a by-chance elevated (or lowered) relative risk changed towards the null from one occasion to another, was thereby tackled.

The geo-mapping methodology proved to be rapid and robust albeit, as always, depending on the quality of the input data. The high coverage of data $(>75 \%)$ indicates that the findings are valid for the entire population. There is always a risk that non-examined children or children of families avoiding dental visits have an impaired oral health but that risk was low in the present study groups. In fact, the dominating reason for not being examined was a prolonged recall interval (up to 18 months) due to an estimated low caries risk [10].

The finding of an increased polarization of caries risk in spite of a generally improved dental health over the 4-year period was unwanted but not unexpected in the light of current papers on caries trends [17-20]. The Public Dental Service in the region is strongly encouraged to work actively with CRA and individual recall intervals. It should however be stressed that the overall cumulative caries burden in the present study population was low from an international perspective [21]. Nevertheless, the present timetrend geo-maps enable more detailed analyses for the possible local reasons for the certain changes in SmRRs on parish and/or clinic level. For example, the parish in the northern part of the region that fell from top-10 to the mid-range in four years has seen a rapid growth and urbanization with relocation of many young families. It is also important to realize that the ranking is relative. One parish with unchanged and low caries risk might be "passed" by one slightly improving its caries risk. Likewise, a decreased SmRR ranking might not necessarily mean that the caries risk de facto is significantly increased.

Our purpose was to disclose changes geographical patterns in childhood caries risk over time, without adjusting the parish-level relative risks (SmRRs) for contextual socioeconomic characteristics (which are geographically confounded factors [22]). If a parallel change in a socioeconomic determinant of parish-level relative risk occurs, further adjustments of the SmRR can provide insights to what extent the altered contextual position had an impact. However, we did not observe any considerable parallel changes in the available contextual socioeconomic indicators. Beyond the contextual socioeconomic data, we had lack of data on possible explanatory variables. Of course, it is essential to collect such data for planned 
assessments of preventive care. In fact, in the Halland region, there is a plan to collect data from the dental clinics regarding preventive care and, also, a proposal to reallocate resources for preventive care. Notwithstanding those planned efforts, we have demonstrated that our proposed method based on repeated geo-maps provides a useful assessment tool.

We are fully aware that there is limited evidence for methods to bridge inequalities in early childhood caries and that compliance for both self-applied and professional measures is a paramount concern [23]. However, for the preschool ages with adult responsibility, several controlled field trials have demonstrated that education, motivational interviews, coaching, tooth brushing and fluoride can significantly improve oral health and especially in vulnerable and deprived populations [24,25]. Geo-maps addressing time trends can hopefully be used to increase the understanding and improve the quality of follow-ups in future studies with the goal to optimize the strategies to eradicate early childhood caries. Indeed, our findings strongly indicate that repeated geo-maps over time could be useful to monitor the effect of populationbased interventions as well as targeted programs for individuals with increased caries risk. Interestingly, feedback on interventions and programs might be available in a relative short time span. The effectiveness of such programs is probably not limited to dentistry but can also be valid for current and future school-based activities such as promoting a healthy lifestyle and fighting over-weight and obesity in childhood. We reinforce the assumption that the common risk factor approach (highsugar diet, fats, etc.) should be at focus for the prevention of both dental and medical diseases [10].

\section{Conclusion}

Geo-maps based on caries risk can be used to monitor changes in caries risk over time. Thus, geo-mapping offers a convenient tool for evaluating effectiveness of tailored health promotion and preventive care in child populations.

\section{Competing interests}

The authors declare that they have no competing interests.

\section{Acknowledgements}

The authors are grateful to the smooth cooperation with the Public Dental Service in Halland and to Mr. Ralf Rittner for constructing the maps. The study was financially supported by Region Halland, Sweden.

\section{Author details}

'Department of Research and Development, Halland Hospital, SE-301 85, Halmstad, Sweden. ${ }^{2}$ Department of Occupational and Environmental Medicine, Lund University, SE-221 85, Lund, Sweden. ${ }^{3}$ Section of Community and Preventive Dentistry, Maxillofacial Unit, Halland Hospital, SE-301 85 Halmstad, Sweden. ${ }^{4}$ Department of Cariology, Endodontics, Pediatric Dentistry and Clinical Genetics, Institute of Dentistry, Faculty of Health and Medical Sciences, University of Copenhagen, Nørre Allé 20, 2200, Copenhagen N, Denmark.

\section{Authors' contributions}

All of the listed authors contributed to the conduct of the study. US, AH and ST analyzed and interpreted the data. US and ST drafted the manuscript. KE provided technical and administrative support. All authors approved the final version of this manuscript.

Received: 6 October 2011 Accepted: 17 April 2012

Published: 17 April 2012

\section{References}

1. Locker D: Deprivation and oral health: a review. Community Dent Oral Epidemiol 2000, 28:161-169.

2. Sabbah W, Tsakos G, Chandola T, Sheiham A, Watt RG: Social gradients in oral and general health. J Dent Res 2007, 86:992-996.

3. Bedi R, Quarrell I, Kippen A: The dental health of 10-year-old children attending multi-racial schools in Greater Glasgow. Br Dent J 1991, 170:182-185.

4. Conway DI, Quarrell I, McCall DR, Gilmour H, Bedi R, Macpherson LM: Dental caries in 5-year-old children attending multi-ethnic schools in Greater Glasgow-the impact of ethnic background and levels of deprivation. Community Dent Health 2007, 24:161-165.

5. Christensen LB, Twetman S, Sundby A: Oral health in children and adolescents with different socio-cultural and socio-economic backgrounds. Acta Odonto/ Scand 2010, 68:34-42.

6. Twetman S, Fontana M: Patient caries risk assessment. Monogr Oral Sci 2009, 21:91-101

7. Watt $R$, Sheiham $A$ : Inequalities in oral health: a review of the evidence and recommendations for action. Br Dent J 1999, 187:6-12.

8. Watt RG: Strategies and approaches in oral disease prevention and health promotion. Bull World Health Organ 2005, 83:711-718.

9. Petersen PE: Global policy for improvement of oral health in the $21 \mathrm{st}$ century-implications to oral health research of World Health Assembly 2007, World Health Organization. Community Dent Oral Epidemiol 2009, 37:1-8.

10. Strömberg U, Magnusson K, Holmén A, Twetman S: Geo-mapping of caries risk in childern and adolescents - a novel approach for allocation of preventive care. BMC Oral Health 2011, 11:26.

11. World Health Organisation: Oral Health Surveys - Basic Methods 4th edn. Geneva: World Health Organisation; 1997.

12. Pascutto C, Wakefield JC, Best NG, Richardson S, Bernardinelli L, Staines A, Elliot P: Statistical issues in the analysis of disease mapping data. Stat Med 2000, 19:2493-2519.

13. Small area statistics unit [http://www.sahsu.org/sahsu_studies.php\#RIF]

14. Beale L, Abellan JJ, Hodgson S, Jarup L: Methodologic issues and approaches to spatial epidemiology. Environ Health Perspect 2008, 116:1105-1110.

15. The bugs project [http://www.mrc-bsu.cam.ac.uk/bugs]

16. Richardson S, Thomson A, Best N, Elliot P: Interpreting posterior relative risk estimates in disease-mapping studies. Environ Health Perspect 2004 112:1016-1025.

17. Jamieson LM, Armfield JM, Roberts-Thomson KF: Dental caries trends among indigenous and non-indigenous Australian children. Community Dent Health 2007, 24:238-246.

18. Stecksén-Blicks C, Kieri C, Nyman JE, Pilebro C, Borssén E: Caries prevalence and background factors in Swedish 4-year-old children - a 40-year perspective. Int J Paediatr Dent 2008, 18:317-324.

19. Dye BA, Arevalo O, Vargas CM: Trends in paediatric dental caries by poverty status in the United States, 1988-1994 and 1999-2004. Int J Paediatr Dent 2010, 20:132-143.

20. Ditmyer M, Dounis G, Mobley C, Schwarz E: Inequalities of caries experience in Nevada youth expressed by DMFT index vs. Significant Caries Index (SiC) over time. BMC Oral Health 2011, 11:12.

21. Davies GM, Jones CM, Monaghan N, Morgan MZ, Pine CM, Pitts NB, Neville $J S$, Rooney E: The caries experience of 5 year-old children in Scotland, Wales and England in 2007-2008 and the impact of consent arrangements. Reports of co-ordinated surveys using BASCD criteria. Community Dent Health 2011, 28:5-11.

22. Pereira SM, Ambrosano GMB, Cortellazzi KL, Tagliaferro EPS, Vettorazzi CA, Ferraz SFB, Meneghim MC, Pereira AC: Geographic Information Systems (GIS) in Assessing Dental Health. Int J Environ Res Public Health 2010, 7:2423-2436. 
23. Twetman S: Prevention of early childhood caries (ECC)-review of literature published 1998-2007. Eur Arch Paediatr Dent 2008, 9:12-18.

24. Tinanoff N, Reisine S: Update on early childhood caries since the Surgeon General's Report. Acad Pediatr 2009, 9:396-403.

25. Wennhall I, Norlund A, Matsson L, Twetman S: Cost-analysis of an oral health outreach program for preschool children in a low socioeconomic multicultural area in Sweden. Swed Dent J 2010, 34:1-7.

doi:10.1186/1472-6831-12-9

Cite this article as: Strömberg et al: Geo-mapping of time trends in

childhood caries risk - a method for assessment of preventive care. BMC Oral Health 2012 12:9.

\section{Submit your next manuscript to BioMed Central and take full advantage of:}

- Convenient online submission

- Thorough peer review

- No space constraints or color figure charges

- Immediate publication on acceptance

- Inclusion in PubMed, CAS, Scopus and Google Scholar

- Research which is freely available for redistribution 